\title{
Reducir la mortalidad relacionada con las drogas en Europa parece una cuestión de salud pública irresoluble
}

\section{Reducing drug related mortality in Europe - a seemingly intractable public health issue} Isabelle Giraudon; Julian Vicente; João Matias;
Jane Mounteney; Paul Griffiths
European Monitoring Centre for Drugs and Drug Addiction (EMCDDA). Lisbon, Portugal.
Enviar correspondencia a:

Isabelle Giraudon.

Health consequences.

Prevalence, consequences and data management unit.

EMCDDA, Cais do Sodré, 1249-289 Lisbon, Portugal.

Tel. (351) 211210339 • Fax (351) 213584441.

Email: isabelle.giraudon@emcdda.europa.eu

\section{Resumen}

En base al análisis de los datos de más de 30 estudios de cohortes, se puede estimar que cada año mueren en Europa entre 10.000 y 20.000 usuarios de opiáceos. Generalmente las tasas de mortalidad anual se sitúan entre 10-20/1000, representando un exceso de mortalidad 10 a 20 veces superior al esperado para el grupo de edad. La mayoría de las muertes suceden entre hombres de alrededor de 35 años. Se pueden identificar cuatro grandes grupos de causas de muerte: sobredosis, enfermedades, suicidio y traumas. Mientras que la mortalidad relacionada con el VIH esta en disminución, otras causas de muerte han mostrado pocos signos de descenso en los últimos años. Particularmente preocupantes son las sobredosis, que representan 6.300 a 8.400 muertes cada año. El hecho de que las muertes no hayan disminuido es sorprendente, dada la expansión del tratamiento y otros servicios. Varios factores interrelacionados podrian ayudar a explicar este problema irresoluble, como son una creciente vulnerabilidad de una cohorte de usuarios que envejecen, el uso de alcohol y otras drogas, una salud altamente deteriorada, conductas de riesgo, la co-morbilidad, y la exclusión social y marginalización. Reducir la morbilidad general entre los usuarios de heroina continua siendo un tema clave para los servicios europeos de salud pública. Para conseguirlo es necesario profundizar en la comprensión y la actuación sobre los factores asociados, directa 0 indirectamente, a la mortalidad por el uso de drogas.

Palabras clave: mortalidad, sobredosis, VIH, usuarios de drogas, Europa.

\section{Abstract}

Drawing on an analysis of data from over 30 cohort studies, it can be estimated that between 10.000 and 20.000 opioid users die each year in Europe. Typically, annual mortality rates are between 10-20/1000, representing an excess mortality 10 to 20 times greater than expected. Most deaths occur among males in their mid-thirties. Four broad categories of cause of death can be identified: overdoses, diseases, suicide and trauma. While the long term trend in HIV related mortality among drug users is downwards, other causes of mortality have shown little sign of decreasing in recent years. Of particular concern are overdoses which account for 6300 to 8400 deaths reported annually. The fact that deaths have not decreased is surprising given the scaling up of treatment and other services. Opioid substitution treatment in particular is known to be protective and the numbers of those in substitution treatment in Europe has increased dramatically. A number of interrelated factors may help explain this intractable problem. These include: the possibility of an aging cohort becoming more vulnerable; the use of alcohol and other drugs; high levels of ill-health, risk behaviour, and co-morbidity; and social exclusion and marginalisation. Reducing overall morbidity among heroin users remains a key issue for Europe's public health services. More efforts are required to better understand and target both the direct and indirect factors associated with mortality among problem drugs users, if this major health cost associated with drug consumption is to be reduced.

Key words: mortality, overdose, HIV, drug users, Europe. 
S ince the 1970's, heroin use and drug injection have been at the heart of the European drug problem, so much so, that injecting opiate use, has become virtually synonymous in many people's minds with the idea of problem drug use itself. The political and response agenda was galvanised by the emergence of HIV in the mid 1980s, which posed a new and alarming threat, both to drug users and the wider community. For the last two decades, both reducing injecting risk behaviour and engaging with the 'hard to reach' have been paramount issues for both the development of drug services, and the accompanying political discourse. However recently, there has been something of a change. The drugs agenda in many countries is now concerned with a broader set of topics, behaviours and substances. This has happened at a time when the popularity of injecting has been in decline and heroin users appear to be an ageing group. Opiate treatment services have expanded dramatically and it is estimated that there are now around three quarters of a million substitution treatments delivered annually in Europe (EMCDDA, 2011b). Over the last decade, harm reduction services have also increased, if unevenly. In many countries, heroin users who were once regarded as a hidden population are now more likely to be characterised by multiple service use. These developments can be seen to have had a profound impact on HIV infection. However, if we step back from this restricted viewpoint, and take a longer term view on the mortality of those with severe and longterm drug problems, the more depressing observation is that reducing elevated levels of mortality, which is an indicator of health damage among this group, has come to represent a far more intractable public health challenge than might have been expected.

As recent data from Greece and Romania has shown, the risk of outbreaks of drug related HIV remains with us in Europe (EMCDDA \& ECDC, 2011). However, despite these current concerns, the overall situation still looks positive in terms of both international and temporal points of comparison. The EMCDDA estimated that there were around 2000 HIV/AIDS-related deaths in Europe attributable to injecting drug use in $2008^{(1)}$. Nine out of 10 of these were reported in just four countries: Spain, Italy, Portugal and France. With the implementation of HAART, recent studies show that HIV/AIDS is responsible for a much smaller share of deaths among drug users, compared to studies conducted in the 90s (Bargagli et al., 2006). Despite recent outbreaks, the overall medium term trend in new infection rates is for the most part downward. Moreover, in many countries injecting is becoming an increasingly less popular mode of drug administration, as evident in the fact that the majority of heroin users entering drug treatment for the first time in Europe are now no longer using their drugs by this route of administration. In many countries, heroin use itself also appears to be a behaviour with declining popularity amongst young people.

If the long term trend in HIV related mortality among drug users is a positive one, this conclusion sits in stark

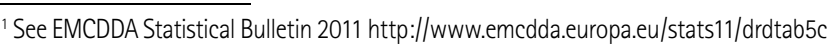

contrast to other forms of mortality within this group, in particular overdoses which remain very high (6300 to 8400 deaths per year during 1995-2008) and with little sign of decrease in recent years (EMCDDA, 2011b). This is surprising in the context of the scaling up of treatment and other services for problem opiate users, a group using a drug known to be disproportionately associated with mortality, and where treatment attendance is known to provide protection. In a new analysis the European Monitoring Centre for Drugs and Drug Addiction (EMCDDA) estimates that between 10000 and 20000 problem opioid users die each year in Europe (EMCDDA, 2011a). This finding is based on a review of the available literature, an analysis of data from over 30 cohort studies of problem drug users and by a special data collection carried out in 12 EU Member States, as well as Croatia and Norway.

Most of the cohort studies analysed reported mortality rates in the range of 10-20 per thousand per year. This means $1-2 \%$ of the cohort members die every year, and over a 10 -year period, between $10 \%$ and $20 \%$ of the group can be expected to be dead. No clear 'regional' patterns are observable in the data, although cohorts in the south and south east of Europe tend to show lower mortality rates compared to others: 9/1000 person-years (PY) in Romania, 6 to $15 / 1000$ in Czech republic, 11/1000 in Croatia and Germany, 12/1000 in Bulgaria and Italy, 13 to 22/1000 in the United Kingdom, 18/1000 in Poland, 11 to 22/1000 in Latvia, $19 / 1000$ in Sweden and 23/1000 in Norway. Mortality for drug users is roughly 10 to 20 times that of the general population of the same age and gender. Most participants in the studies are males (about 80\%), mostly heroin users engaged at point of recruitment in treatment for opioid dependence. Those who die are typically in their early to mid-thirties although some countries now report that over a third of their overdose cases are aged 40 years or older.

Four broad categories of causes of deaths can be identified: overdoses, diseases, suicide and trauma. Roughly, between one-third and half of deaths among drug users are due to overdose, while between one-fifth and two-fifths are due to suicide and trauma, and less than a tenth is due to HIV/AIDS. Around 7000 to 8000 overdose deaths are reported every year in Europe (Vicente, Giraudon, Matias, Hedrich, \& Wiessing, 2009). Opioids, particularly heroin, are the drugs most often implicated in overdoses, often in combination with other substances, with alcohol and benzodiazepines being frequently cited. Despite some public impressions, overdose deaths appear uncommon in neophyte users and are primarily associated with long term and chronic drug using careers (Darke, Degenhardt, \& Mattick, 2007).

While drug overdose deaths are a problem clearly identified as associated with opiate use, more often overlooked is the considerable level of excess mortality this group suffers over time associated with other causes. These include chronic health problems such as liver disease, cardiovascular and pulmonary conditions, as well as cancer and infections. Deaths from trauma (including traffic accidents, falls, drowning, injuries, assault, homicide) are also far more frequently 
reported among chronic illicit drug users than among the general population. Violent deaths may be more closely related to social exclusion, involvement in the drug market and criminality, mental health problems and the life circumstances of problem drug users, than to drug use itself. Suicide and self harm also present a major clinical challenge for those treating problem drug users. Depression is a key risk factor for suicide, and the prevalence of depressive disorders among problem drug users is high. The suicide rate among heroin users has been estimated to be 14 times that in the general population (Darke et al., 2007). Taken as a whole, chronic opiate users are at elevated risk of morbidity and mortality through a combination of factors both directly and indirectly related to their drug use, and these factors may act in combination to increase the overall mortality found in cohorts. It is also likely that as cohorts age they become more vulnerable to some of these factors (Clausen, Waal, Thoresen, \& Gossop, 2009; EMCDDA, 2011a; Stenbacka, Leifman, \& Romelsjo, 2010). This, in part, could help explain why in Europe an increase in those in contact with treatment services has not resulted in any easily observable impact on reported overdose deaths over time at the population level.

This is a particular challenge for public health responses as studies suggest that many deaths could be prevented as many of the risk factors for mortality are known. Risk of death is increased by previous overdose, injecting compared to other forms of administration, attempted suicide, polydrug use, somatic and psychiatric co-morbidity, and not being enrolled in drug treatment. Being in treatment, particularly opioid substitution treatment is known to be strongly protective against mortality (Bargagli, Davoli, Minozzi, Vecchi, \& Perucci, 2007; Davoli et al., 2007; Degenhardt et al., 2009; Degenhardt et al., 2011a; Darke, Williamson, Ross, \& Teesson, 2005; Brugal et al., 2005), however many opiate users are known to move in and out of treatment over time - rather than maintain a steady contact. This is important as evidence suggests that the periods following release from prison and dropping out of opioid substitution treatment are times of particularly high overdose risk for drug users, due to reduced levels of opioid tolerance (Merrall et al., 2010; WHO Regional Office for Europe, 2010). So much so that, the benefits to risks of short treatment episodes for opiate users are questionable. Initiation of opioid substitution treatment can be a risky period as well (Clausen, Anchersen, \& Waal, 2008; Cornish, Macleod, Strang, Vickerman, \& Hickman, 2010). Currently, overdose prevention among opiate users does not receive the attention that the data suggests it clearly deserves. This is beginning to change in many countries with a greater priority given to prevention work. Current approaches include education of drug users on the risks associated with polydrug use and on recognising and managing overdoses when they occur. Innovative approaches under development in some countries include the provision of take-home doses of the opiate antagonist naloxone, given to heroin users, their peers and family. Awareness is also growing of the importance of continuance of care for those leaving custodial settings and the need to address overdose risks for those leaving both treatment and prison. Nonetheless, it is clear that more needs to be done if the current high level of mortality associated with drug overdose is to be reduced.

It is a discouraging conclusion that over the last 20 years in Europe, with the exception of the HIV component (EMCDDA, 2011b), we have not observed a large decrease in mortality rates among opiate users (Darke et al., 2007; Degenhardt et al., 2011a; EMCDDA, 2011a; EMCDDA, 2011b). This is despite a dramatic improvement in the coverage of opioid substitution treatment. The long-term stability of mortality rates can even be argued to put into question what we understand about the impact of drug treatment when viewed over the longer term and at the population level. It also raises the question of whether Europe's opiate users are becoming more vulnerable? This could possybly be a result of their long term drug use, or changes in consumption patterns, such as the increased use of alcohol or other substances. Vulnerability is also likely to be increasing simply through the natural aging process occurring within a group with high rates of existing health problems and one whose health may also be at elevated risk through lifestyle and other health risks behaviours. This would point to the value of specialist drug services addressing lifestyle issues such as smoking and diet, and establishing good referral links with generic healthcare and screening services. As many specialist drug services are now finding themselves dealing with an opiate using client group who are in their middle age, or older, this is necessarily going to mean a change in perspective with more focus given to the health problems associated with ageing.

As engagement in drug treatment is known to be protective in respect to overdose risk this raises important research and service development issues especially in regard to what factors can ensure treatment continuance. Beyond this we also need to explore how to intervene effectively to reduce the risks for those not currently in contact with services. This editorial has touched on a range of prevention responses to overdose, from opioid substitution treatment to take-home naloxone, and pointed out that many of the risk factors for overdose are now known. However in Europe, despite some examples of good and innovative practice, overall this knowledge has not resulted in the delivery of effective interventions. Even simple awareness raising activities focussing on the known high risk periods, and behaviours, may prove valuable both to professionals and those at risk. More generally we still require more implementation studies, demonstration projects and a better understanding of what mix of approaches will be necessary to be protective at the population level.

The data also suggest that trauma and suicide deaths should be given a greater research priority, as mortality related to these causes is sustained over time. From a methodological point of view, these data also underline the value of cohort studies as they provide a longer term window on drug related behaviour and help us to better understand the natural history of drug use in relation to health outcomes. Elevated morbidity is likely to stem, in part at least, from the interaction of long term drug use with, broader issues, such as social marginalisation, isolation, and 
poverty. This may help explain why the problem appears so intractable, however it also points to the need for of a more holistic approach, which sees drug problems within the broader context of health and social disadvantage. Here drug services can also play a valuable role in acting as a conduit to generic care for a group whose access to primary health and social support services may be limited.

In addition to the need to respond adequately to morbidity among heroin users, public health responses in Europe are increasingly challenged by the changing nature of the drug problem. The growing importance of stimulants and synthetic drugs in particular, is forcing us to reevaluate our research and response agenda as we begin to understand better the effect of these changes on public health. In terms of morbidity, for example, the cardiotoxicity of cocaine warrants greater attention as the use of this drug has increased, and there is growing evidence from some countries of associated harms (Degenhardt et al., 2011b; EMCDDA, 2011b). Stimulant drugs may also be linked with acute mental health problems, as well as violence, or the risk of becoming a victim of violence. Women for example, are reported to be at particular risk of experiencing a trauma-related death, including assault and murder (Darke S et al., 2007; EMCDDA, 2011a). The use of synthetic opioids, which also appears to be increasing in parts of Europe, may be linked to significant morbidity and mortality. To date, the best documented example relates to deaths caused by fentanyl use in Estonia (Talu et al., 2010). In the United States and elsewhere, overdose from the misuse

\section{References}

Bargagli, A. M., Davoli, M., Minozzi, S., Vecchi, S., \& Perucci, C. A. (2007). A Systematic Review of Observational Studies on Treatment of Opioid Dependence Geneva, Switzerland, WHO. Retrieved from: http://www.who.int/substance_abuse/activities/observational_ studies_treatment.pdf

Bargagli, A. M., Hickman, M., Davoli, M., Perucci, C. A., Schifano, P., Buster, M. et al. (2006). Drug-related mortality and its impact on adult mortality in eight European countries. European Journal of Public Health, 16, 198-202. doi:10.1093/eurpub/cki168

Brugal, M. T., Domingo-Salvany, A., Puig, R., Barrio, G., Garcia de, 0. P., \& de la Fuente, L. (2005). Evaluating the impact of methadone maintenance programmes on mortality due to overdose and aids in a cohort of heroin users in Spain. Addiction, 100, 981-989. doi:10.1111/j.1360-0443.2005.01089.x

Clausen, T., Anchersen, K., \& Waal, H. (2008). Mortality prior to, during and after opioid maintenance treatment (OMT): a national prospective cross-registry study. Drug and Alcohol Dependence., 94, 151-157. doi:10.1016/j.drugalcdep.2007.11.003

Clausen, T., Waal, H., Thoresen, M., \& Gossop, M. (2009). Mortality among opiate users: opioid maintenance therapy, age and causes of death. Addiction, 104, 1356-1362. doi:10.1111/j.13600443.2009.02570.x of prescription drugs (mainly opioids painkillers) has become an important public health problem. The situation in Europe is somewhat different, but the misuse of medicinal products, either diverted from the licit market, illicitly produced or imported from outside the EU, appears to be becoming more common. Currently, our data collection sources are poorly configured to monitor the use of these types of drugs or the problems they may cause. Taken together this means that not only does Europe need to do better in the future in addressing the seemingly intractable problem of excess mortality among the users of established drugs of abuse, like heroin, but also there is a growing need to improve our monitoring and understanding of both the morbidity and mortality that is likely to be associated with stimulants, in particular cocaine, and newer and more novel substances.

\section{Acknowledgment}

We would like to acknowledge the contribution of the Reitox Network of National Drug Focal Points, and the EMCDDA expert group on mortality, whose work informed the drafting of this editorial.

\section{Competing interest}

No conflicts of interest are declared.

Cornish, R., Macleod, J., Strang, J., Vickerman, P., \& Hickman, M. (2010). Risk of death during and after opiate substitution treatment in primary care: prospective observational study in UK General Practice Research Database. British Medical Journal, (7779), 928. doi:10.1136/bmj.c5475

Darke S, Degenhardt, L., \& Mattick, R. (2007). Mortality amongst illicit drug users: epidemiology, causes and interventions Cambridge University Press.

Darke, S., Williamson, A., Ross, J., \& Teesson, M. (2005). Non-fatal heroin overdose, treatment exposure and client characteristics: findings from the Australian treatment outcome study (ATOS). Drug and Alcohol Review, 24, 425-432. doi:10.1080/09595230500286005

Davoli, M., Bargagli, A. M., Perucci, C. A., Schifano, P., Belleudi, V., Hickman, M.,... VEdeTTE Study Group (2007). Risk of fatal overdose during and after specialist drug treatment: the VEdeTTE study, a national multi-site prospective cohort study. Addiction, 102, 1954-1959. doi:10.1111/j.1360-0443.2007.02025.X

Degenhardt, L., Bucello, C., Mathers, B., Briegleb, C., Ali, H., Hickman, M. \& McLaren, J. (2011a). Mortality among regular or dependent users of heroin and other opioids: a systematic review and metaanalysis of cohort studies. Addiction, 106, 32-51. doi:10.1111/ j.1360-0443.2010.03140.x

Degenhardt, L., Randall, D., Hall, W., Law, M., Butler, T., \& Burns, L. (2009). Mortality among clients of a state-wide opioid pharmacotherapy 
program over 20 years: risk factors and lives saved. Drug and Alcohol Dependendence, 105, 9-15. doi:10.1016/j.drugalcdep.2009.05.021

Degenhardt, L., Singleton, J., Calabria, B., McLaren, J., Kerr, T., Mehta, S.,... Hall, W.D. (2011b). Mortality among cocaine users: a systematic review of cohort studies. Drug and Alcohol Dependence, 113, 88-95. doi:10.1016/j.drugalcdep.2010.07.026

EMCDDA. (2011a). Mortality related to drug use in Europe: public health implications Luxembourg: Publications Office of the European Union. Retrieved from: http://www.emcdda.europa.eu/publications/ selected-issues/mortality

EMCDDA. (2011b). The state of the drugs problem in Europe. Annual report 2011 Luxembourg: Publications Office of the European Union. Retrieved from: http://www.emcdda.europa.eu/publications/annualreport/2011

EMCDDA, \& ECDC. (2011). Joint ECDC and EMCDDA rapid risk assessment HIV in Injecting Drug Users in the EU, following a reported increase of cases in Romania and Greece. doi:10.2810/50417 Retrieved from: http://www.emcdda.europa.eu/html.cfm/index146510EN.html

Merrall, E. L., Kariminia, A., Binswanger, I. A., Hobbs, M. S., Farrell, M., Marsden, J.,... Bird, S. M. (2010). Meta-analysis of drug-related deaths soon after release from prison. Addiction, 105, 1545-1554. doi:10.1111/j.1360-0443.2010.02990.x

Stenbacka, M., Leifman, A., \& Romelsjo, A. (2010). Mortality and cause of death among 1705 illicit drug users: a 37 year follow up. Drug and Alcohol Review, 29, 21-27. doi:10.1111/j.1465-3362.2009.00075.x

Talu, A., Rajaleid, K., Abel-Ollo, K., Ruutel, K., Rahu, M., Rhodes, T.,... Uusküla, A. (2010). HIV infection and risk behaviour of primary fentanyl and amphetamine injectors in Tallinn, Estonia: implications for intervention. International Journal of Drug Policy, 21, 56-63. doi:10.1016/j.drugpo.2009.02.007

Vicente, J., Giraudon, I., Matias, J., Hedrich, D., \& Wiessing, L. (2009). Rebound of overdose mortality in the European Union 20032005: findings from the 2008 EMCDDA Annual Report. Euro. Surveill, 14(2).

WHO Regional Office for Europe. (2010). Prevention of acute drugrelated mortality in prison populations during the immediate postrelease period. Copenhagen: WHO Regional Office for Europe. Retrieved from: http://www.euro.who.int/en/what-we-publish/ abstracts/prevention-of-acute-drug-related-mortality-in-prisonpopulations-during-the-immediate-post-release-period 
